Artigos

\title{
Trabajo infantil y salud Revisión de literatura argentina y exploración de enfoques alternativos
}

\author{
Trabalho infantil e saúde \\ Revisão da literatura argentina e exploração de enfoques alternativos \\ Child labour and health \\ Review of Argentine studies and exploration of alternative perspectives
}

Laura Frasco Zuker*

\begin{abstract}
Resumen: El trabajo infantil es uno de los fenómenos más condenados dentro del campo de problemáticas de la niñez. En Argentina, las leyes y programas que se aplican con relación a la regulación del trabajo realizado por niños/as incorporan las recomendaciones de la Organización Internacional del Trabajo, que propone erradicar el trabajo infantil en general y de manera urgente si se trata de sus peores formas. La condena moral y la ilegalidad del trabajo infantil se expresan en una falta de investigación sistemática que permita contar con estadísticas actualizadas. Según indican investigaciones recientes, son especialmente escasos los estudios que se focalizan en la relación entre trabajo infantil y salud. En este artículo se realiza una revisión de dichos estudios con el objetivo de señalar sus características y alcances y, por otro lado, se exploran enfoques alternativos que contribuyen a acrecentar la comprensión del tema. El argumento central plantea que el mentado riesgo para la salud que implica el trabajo infantil es a la vez una concepción moral sobre las familias. Palabras clave: Infancia. Trabajo. Salud. Revisión.
\end{abstract}

Resumo: O trabalho infantil é um dos fenômenos mais condenados no campo das problemáticas da infância. Na Argentina, as leis e programas que são aplicados em relação à regulamentação do trabalho realizado por crianças incorporam as recomendações da Organização Internacional do Trabalho, que se propõe a erradicar o trabalho infantil em geral e de forma urgente se estas se apresentam nas suas piores formas. A condenação moral e a ilegalidade do trabalho infantil são expressas na falta de pesquisa sistemática que permita contar com estatísticas atualizadas. De acordo com pesquisas recentes, existem especialmente poucos estudos que se concentram na relação entre trabalho infantil e saúde. Neste artigo, uma revisão desses estudos é realizada para indicar suas características e abrangência e, por outro lado, são exploradas abordagens alternativas que se espera que contribuam para aumentar a compreensão do assunto. $\mathrm{O}$ argumento central é que o risco para a saúde implicado pelo trabalho infantil é ao mesmo tempo uma concepção moral das famílias.

Palavras-chave: Infância. Trabalho. Saúde. Revisão.

\footnotetext{
* Universidad de Buenos Aires (UBA, Ciudad Autonoma de Buenos Aires, Argentina; grid. 7345.5) y Universidad Nacional de La Matanza (UNLaM, San Justo, Buenos Aires, Argentina).

autor.datos_biográficos
}

Civitas, Porto Alegre, v. 18 , n. 2, p. 397-410, mayo-agosto 2018 


\begin{abstract}
Child labour is one of the most condemned phenomena in the field of childhood problems. In Argentina, the laws and programs that are applied in relation to the regulation of labour carried out by children incorporate the recommendations of the International Labor Organization, which proposes to eradicate child labour in general and urgently if it is their worst shapes. The moral condemnation and illegality of child labour are expressed in a lack of systematic research that allows for up-to-date statistics. According to recent research, there are especially few studies that focus on the relationship between child labour and health. In this article, a review of these studies is carried out in order to indicate their characteristics and scope and, on the other hand, alternative approaches are explored that are expected to contribute to increase the understanding of the subject. The argument is that the risk to health implied by child labour is at the same time a moral conception of families.
\end{abstract}

Keywords: Childhood. Labour. Health. Review.

\title{
Introducción
}

El trabajo infantil es un fenómeno que se ha vuelto objeto de investigación y de regulación estatal en Argentina desde fines del siglo XIX (Lobato, 2007). Es considerado como uno de los principales problemas de la infancia a nivel mundial y ha dado lugar a numerosas investigaciones de diversos campos disciplinares. Desde comienzos de la década de 1990 se instaló más fuertemente en la agenda de la infancia argentina (Macri, 2012) en el contexto de los cambios institucionales y legislativos vinculados a la sanción de la Convención Internacional sobre los Derechos del Niño (CDN). ${ }^{1}$ La adhesión a normativas internacionales y aplicación de leyes tendientes a la prevención del trabajo infantil ha sido una de las vías garantizar sus derechos básicos, entre ellos la escolarización y salud. Si bien se sostiene que la salud es vulnerada por el trabajo infantil, son pocos los estudios que se focalizan en este aspecto.

\footnotetext{
${ }^{1}$ La incorporación de la CDN a la Constitución Nacional argentina, significa que el país está obligado a garantizar a los niños y adolescentes los derechos civiles, políticos, sociales, culturales y económicos. Este instrumento los eleva a la categoría de sujetos de derecho y establece obligaciones de los estados y de las familias hacia ellos. Este tratado, el más completo sobre los derechos de los niños, apunta a brindar una amplia protección, como la de ser amparado contra la explotación económica y la realización de todo trabajo que pueda resultar peligroso o menoscabar su educación, o ser nocivo para su salud o su desarrollo físico, mental, espiritual, moral o social (Art. 32 inc. 1). Insta a los estados parte a adoptar medidas legislativas, administrativas, sociales y educativas para que garanticen su aplicación y establezcan: a) una edad mínima para la admisión en el empleo; b) una reglamentación adecuada de las horas y condiciones de empleo; y c) sanciones económicas o de otra índole para lograr el pleno cumplimiento de sus disposiciones (Art. 32 inc. 2) (Duro, 2007, p. 53-54).
} 
En este artículo se realiza una revisión de literatura argentina sobre trabajo infantil y salud y se exploran enfoques alternativos. Se espera contribuir a comprender mejor el objeto de estudio así como promover una reflexión crítica sobre los alcances y limitaciones de los abordajes de procesos de salud, enfermedad, atención y cuidado centrados en la población infantil.

\section{Trabajo infantil y salud: una relación desatendida}

Pese al creciente interés de las políticas públicas y del ámbito académico por el trabajo infantil, éste ha sido históricamente poco estudiado. ${ }^{2}$ Entre los abordajes más frecuentes de las ciencias sociales en Argentina se encuentran: el análisis de causas y consecuencias del trabajo infantil, la comprensión de la perspectiva de los actores y la relación con la educación y el género (Rausky, 2009). Es habitual encontrar estos temas juntos en investigaciones que recortan el problema privilegiando el ámbito donde ocurre - trabajo infantil rural, urbano, doméstico -, según escalas de análisis - macro o microsociológicas (Rausky, 2015) o según la dimensión temporal - abordado en perspectiva histórica o como fenómeno del presente (Halperín, 2012).

\section{Inspecciones laborales: primeros registros sobre trabajo infantil}

Los primeros informes oficiales que sistematizaron los efectos nocivos del trabajo sobre la salud de los niños/as datan de principios del siglo XX. Estos documentos, realizados por inspectores de trabajo del Departamento Nacional del Trabajo, ${ }^{3}$ incluyen los primeros datos ${ }^{4}$ sistematizados sobre condiciones laborales de los trabajadores argentinos.

\footnotetext{
${ }^{2}$ Este señalamiento debe leerse en el marco de una omisión histórica a los temas de niñez en estudios clásicos de las ciencias sociales (Szulc, 2006)

${ }^{3}$ Los inspectores de trabajo realizaron investigaciones sociales sobre las condiciones laborales y de vida de los trabajadores argentinos que fueron publicadas en informes oficiales. El organismo específico creado para ese fin fue el Departamento Nacional del Trabajo (DNT), establecido en el año 1907 y cuya misión era la recolección, coordinación y publicación de "todos los datos relativos al trabajo para contribuir a las reformas legislativas y administrativas capaces de mejorar la situación social, intelectual y moral de los trabajadores" (Lobato, 2007, p. 146). Entre sus funciones específicas se encontraban "a) investigación, b) elaboración jurídica, c) asesoramiento a organismos públicos, d) vigilancia del cumplimiento de la reglamentación laboral en los locales de trabajo, e) tutela de los intereses comunes del capital y del trabajo, procurando su conciliación en casos de conflicto, f) divulgación. Los inspectores tenían competencia para inspeccionar los establecimientos de trabajo, detectar contravenciones y de mandar la imposición de multas; pero sólo podían ejercer mediación en un conflicto por demanda de las partes involucradas" (Brunatti, Colángelo, Soprano, 2002, p. 87).

${ }^{4}$ Debido a las metodologías con la que se elaboraron, que incluyen observación directa, prolongada y en algunos casos observación participante (Brunatti, Colangelo, Soprano, 2002), resultan fuentes relevantes para las ciencias sociales y particularmente para la antropología.
} 
Los problemas de salud de la población trabajadora fueron atribuidos principalmente a las condiciones de vida y trabajo. Como consecuencia de la masividad del movimiento inmigratorio de principios del siglo XX se produjo un crecimiento abrupto de la población ${ }^{5}$ en las ciudades que se manifestó en la concentración de familias en conventillos o casas similares. El hacinamiento, sumado a una mala alimentación y a las extensas jornadas laborales, generaron la proliferación de enfermedades y la precarización de las condiciones de vida (Suriano, 1990).

Cabe señalar que las inspecciones de trabajo centraron sus observaciones en fábricas y talleres en la ciudad de Buenos Aires (Lobato, 2013), por lo que las descripciones sobre enfermedades, accidentes y falta de regulaciones están centradas en esos espacios. ${ }^{6}$ Los trabajos más habituales en las calles de la ciudad de Buenos Aires eran la venta de diarios, cirujeo, mendicidad, lustrabotas, mensajería, cuidado de carros o caballos, recolección de desperdicios e incluso prostitución (Zapiola, 2009). Mientras que las actividades laborales y lúdicas en el espacio público eran consideradas peligrosas para los/as niños/as porque podían conducir al delito, el trabajo infantil en las fábricas era aceptado por las elites porteñas porque funcionaba como elemento disciplinador en tanto que integraba a los/as niños/as a la actividad productiva. Tal como señala Macri (2005), resulta evidente que coexistían diferentes éticas sobre el trabajo infantoadolescente en una misma época: la ética del riesgo, que planteaba el control del trabajo, sobre todo el callejero y la ética cercana al calvinismo, para la cual el trabajo en el taller era una de las vías de reinserción social de los menores abandonados, delincuentes y/o vagabundos. ${ }^{7}$

En las fábricas y talleres no había medidas de seguridad, por lo que se producían accidentes frecuentemente, situación que fue denunciada por la militante socialista e inspectora de fábricas, Gabriela Lapièrre de Coni. El

\footnotetext{
${ }^{5}$ En el decenio que va desde 1905 a 1915 el crecimiento poblacional en Argentina fue de 2.8 millones de personas (Macri, 2005, p. 34).

${ }^{6}$ No obstante, el trabajo infantil también se encontraba en las calles de Buenos Aires, en zonas rurales y en el servicio doméstico, una de las ocupaciones más representativas de ese período. Según Allemandi (2015), la invisibilización del trabajo doméstico y su sub-registro se debe a que a principios del siglo XX la presencia de niños en el servicio doméstico no se percibía como un problema social por lo que no formó parte de la agenda pública, en contraposición a los casos de trabajo infantil en fábricas y talleres o bien en trabajos callejeros.

${ }^{7}$ Zapiola (2009) se refiere a esta situación de tratamiento diferencial del trabajo infantil en términos de perfil bifronte: "a principios de la década de 1880 la figura del niño trabajador ya había comenzado a ser trazada en sus discursos con un perfil bifronte: instalado en la fábrica o en el taller, debía ser protegido en su integridad física y moral por el gobierno, de ahí las propuestas y las acciones legislativas tendientes a regular el trabajo infantil (no a suprimirlo); pregonando sus mercancías por las calles, ajeno a los controles de los adultos y a cualquier sujeción temporal o espacial, seguía estando en peligro, sí, pero, sobre todo, se convertía en peligroso, por lo que requería de modalidades de tratamiento específicas” (Zapiola, 2009, p. 13-14).
} 
hacinamiento, la falta de ventilación, la escasa luz, las altas temperaturas, el trabajo de varias horas en una misma posición y las emanaciones de productos tóxicos expusieron a los/as niños/as a diversos efectos nocivos para su salud. Entre ellos: intoxicaciones, afecciones en los sistemas digestivo y respiratorio, debilidad muscular, deformaciones en la columna vertebral, cadera y rodillas (Suriano, 1990; Macri, 2005), anemia y necrosis. ${ }^{8}$

El trabajo infantil callejero fue menos descrito que el desarrollado en fábricas debido a la escasez de disposiciones legales que lo regularan y también por la dificultad de caracterizar a una población en permanente estado de circulación (Zapiola, 2009). No obstante, las fuentes resaltan como una de sus principales consecuencias el desgaste físico ocasionado por estar deambulando varias horas al día.

Los cuerpos de las vendedoras se veían afectados por las tareas laborales. El uso de tacos que la "buena presencia" exigía, combinado con la permanencia en pie durante largas jornadas, produjo sentidas dolencias: problemas de circulación sanguínea, retención de líquidos, piernas y pies hinchados, constituyeron malestares frecuentes para muchas de ellas (Queirolo, 2014, p. 42).

Finalmente, en el caso del ámbito rural, la fuente principal que detalla las consecuencias del trabajo rural sobre la salud de los/as niños/as es el informe elaborado por Juan Bialet Massé en 1904. ${ }^{9}$ La exposición a largas jornadas de trabajo, el escaso descanso y las tareas pesadas como el pelado de caña, el trabajo en cultivos, la fabricación de botellas y vidrios - entre otros - "gastaban prematuramente" el organismo de los/as niños/as (Macri, 2005).

\section{Revisión de estudios sobre trabajo infantil y salud}

Según la OIT el trabajo infantil resulta un problema sanitario en tanto que "muchas enfermedades profesionales que producen discapacidad en la edad adulta tienen sus orígenes en la inserción temprana en tareas no adecuadas para el desarrollo infantil" (OIT, 2015, p. 8). Sin embargo, el registro sobre enfermedades y riesgos vinculados al trabajo infantil es escaso.

\footnotetext{
${ }^{8}$ Esta enfermedad era producida por las emanaciones del fósforo (debido a la ausencia de protecciones en las fábricas de fósforos) y deformaba la mandíbula.

9 A pedido del Ministro del Interior Joaquín V. González, Juan Bialet Massé realizó una investigación en el interior del país sobre las condiciones de trabajo de la clase obrera argentina. El informe publicado evidencia la precariedad a la que eran sometidos los/as trabajadores/as en general y en uno de sus capítulos se dedica específicamente al análisis del trabajo realizado por mujeres y niños/as. Disponible en: <trabajo.gba.gov.ar/informacion/masse/Volumen2.pdf> (1 nov. 2017).
} 
En este apartado se presenta una revisión de estudios, en la que se señalan sus características generales, de diversos campos disciplinares que toman como objeto de análisis la salud de los/as niños/as trabajadores/as en Argentina. La mayoría no se enfocan en la salud exclusivamente (Halperín, 2012) sino que lo que hacen junto a otras dimensiones (educación, políticas públicas, etc.). Las publicaciones citadas en el presente artículo también siguen ese patrón, por lo que se incluyen trabajos que analizan la salud como tema central o como un tema más del problema.

Desde la perspectiva de la OIT la falta de datos del sector salud obedece a varias causas: el desconocimiento de los equipos médicos sobre actividades laborales realizadas por niños/as; la ausencia de instrumentos que permitan registrar las situaciones de trabajo infantil en las historias clínicas y la falta de conciencia de las propias familias sobre las consecuencias que el trabajo infantil genera en la salud de los/as niños/as. La falta de investigación sistemática sobre salud de la infancia trabajadora se atribuye a la creencia socialmente compartida de que "los niños no trabajan o que el trabajo que realizan no es tan peligroso" (Ipec, 2011, p. 15). Esta creencia, se argumenta, no permite una toma de conciencia de los "estragos", accidentes, lesiones y enfermedades que produce. Orazi y Stonski (2010) señalan que los médicos no saben o no piensan que muchas lesiones se producen mientras que los/as niños/ as trabajan y, consecuentemente, no registran estas situaciones en las historias clínicas de sus pacientes. Bergesio, Spione, Vargas (2010) refuerzan estos planteos al mostrar, a través de un estudio de caso sobre trabajo infantil en los principales basurales de la provincia de Jujuy, que existe un desconocimiento de los agentes sanitarios de los puestos de salud locales sobre las características de la población y el basural.

Con relación a la hipótesis acerca de la falta de conciencia de las familias sobre los efectos negativos del trabajo en la salud de los/as niños/ as, las investigaciones de Aparicio, Aguilera, Re (2012) sobre familias que trabajan en actividades agropecuarias, aportan datos que van en ese sentido. Observan que cuando hay accidentes se "minimizan" y si los empleadores ofrecen alguna compensación monetaria le prestan más importancia que a las consecuencias físicas ocasionadas (Aparicio, 2009). Por su parte, Cardarelli, Dorrego, Nirenberg (2007) también refieren que hay una falta de problematización sobre riesgos para la salud que implica el trabajo infantil. A través de un estudio enfocado en las percepciones de las familias acerca del trabajo infanto-adolescente en Mendoza, dan cuenta de cómo la salud no es un tema que surja espontáneamente. Solamente cuando es introducido por el entrevistador "las participantes explican que sus hijos están protegidos, 
aludiendo a distintas cuestiones: algunas lo explican refiriéndose a la misma vida que llevan los niños que van inmunizándose; otras también agregan que están protegidos por Dios" (Cardarelli, Dorrego, Nirenberg, 2007, p. 286). A diferencia de estos planteos, Mastrangelo (2009) realiza una investigación etnográfica en la que caracteriza los riesgos laborales asociados al trabajo infantil minero en Misiones. La autora señala que los pozos mineros están rodeados de pinares donde se concentra humedad, creándose condiciones propicias para derrumbes y accidentes traumáticos. Además, otros riesgos típicos del pozo son las picaduras de víboras y roedores.

Las consecuencias del trabajo infantil sobre la salud son también indagadas desde la psicología. Galende y Picco (2001) se preguntan específicamente cuál es la incidencia de los problemas de salud en la "constitución subjetiva" de los/as niños/as que trabajan. Las autoras consideran que el ingreso al trabajo precozmente los expone a múltiples riesgos "desde el punto de vista de su salud física e integridad psíquica". Debido a la independencia temprana de la protección familiar, sostienen, el aparato psíquico de los/as niños/as queda expuesto estímulos perturbadores que pueden obstaculizar procesos de simbolización.

Por último, se retoman los aportes de dos investigaciones del campo de las ciencias sociales, cuyo tema de análisis central es la relación entre trabajo infantil y salud. Silva $(2007 ; 2012 ; 2014)$ considera que la falta de conocimiento sobre dicha relación se ve constreñida por: "el paradigma en salud, las desigualdades sociales y los límites políticos" (Silva, 2012, p.227). Según la autora, los niños que trabajan están expuestos a problemas vinculados a la pobreza (entre ellos la desnutrición, anemia, fatiga y mayor exposición a epidemias) y a condiciones sanitarias deficientes de los lugares de trabajo (que conforman un riesgo adicional) que son "ocultados" por parte de los médicos debido a su "exacerbada defensa del secreto profesional”. Así, concluye, no se puede construir un perfil de morbimortalidad que contribuya a una política de salud preventiva. Para ello, propone partir de una noción de salud que involucre aportes de distintos sectores y que no se restrinja a la enfermedad o muerte (perfil patológico) sino que comprenda al perfil de salud enfermedad como un proceso articulado entre condiciones de vida, trabajo y consumo de las personas. La percepción del niño y su grupo familiar sobre el trabajo y los riesgos a la salud son importantes para poder "distinguir en qué medida el mismo le facilita lograr el sostén de todo el grupo, sirve para escapar de determinada situación de violencia y abuso familiar o permite acceder al consumo de bienes" (Silva, 2007, p. 17). 
Por su parte, Noceti $(2009 ; 2010)$ también entiende a la salud desde un punto de vista integral, como una dimensión compuesta por "distintas esferas de la vida humana" que debe analizarse, junto con el trabajo infantil, en contextos socioculturales específicos que permitan generar políticas públicas adecuadas. A través de una investigación comparativa en dos barrios (uno con presencia de trabajo infantil y el otro no) sobre condiciones de salud, muestra que según la perspectiva de los propios actores sociales los problemas de salud en esos contextos son muy similares y no se adjudican a la presencia/ausencia de trabajo infantil. Las condiciones de vida en los barrios, principalmente la falta de infraestructura urbana, aparecen como las principales afecciones en las consultas médicas.

\section{Exploración de perspectivas alternativas}

La insuficiencia de datos que permitan establecer una relación estrecha entre afecciones a la salud y trabajo infantil es una de las cuestiones que todos los estudios revisados enuncian. A partir de esta constatación resulta relevante indagar qué categorías sustentan aquellas perspectivas que sostienen que el trabajo infantil produce afecciones, estragos y/o daños en la salud de los/as niños/as. Este ejercicio analítico recoge la preocupación planteada por Fonseca y Cardarello (1999) acerca de la reificación de la infancia que muchas veces se encuentra presente en campañas de derechos. Las autoras utilizan la noción de infancia como frente discursivo para marcar que, si bien es una herramienta útil para movilizar acciones estatales (en este caso, por ejemplo, que tiendan a proteger la salud de los/as niños/as que trabajan), la cuestión de la infancia vulnerable en particular suele basarse en imágenes que no tienen correlato en observaciones ni evaluaciones objetivas de la realidad.

Desde la perspectiva de la OIT se apela al carácter universal del crecimiento y desarrollo "independientemente de las pautas culturales o la configuración social" (Ipec, 2011, p. 13). Aquello que va más allá de las diferencias culturales es el proceso de transición hacia la madurez biológica que se extiende hasta los últimos años de la adolescencia. En esta etapa de la vida, siguiendo este argumento, se encuentran características psicológicas y de comportamiento que llevan a los jóvenes a correr riesgos, considerados "suplementarios" si se dan sin supervisión de adultos. Esos riesgos pueden implicar accidentes o enfermedades que resultan más "costosos" para la sociedad si son sufridas por niños, a diferencia de si se trata de adultos. Si bien se reconoce que en el proceso de crecimiento y desarrollo hay una interacción entre "el programa genético, que el individuo recibe de sus padres biológicos y las condiciones ambientales de crianza y la cultura 
de la familia y la comunidad" (Orazi y Stonski, 2010, p. 85) hay una serie de características biológicas que vuelven a los/as niños/as "especialmente vulnerables".

Este último aspecto es problematizado antropológicamente por Colangelo (2012), quien sostiene que los procesos de crecimiento y desarrollo (que suponen un estado de incompletud, inmadurez y fragilidad) se fundan en una concepción del niño

como un ser maleable, vulnerable y dependiente de los adultos - idea que trasciende ampliamente a la medicina - constituye la base de la noción de "crianza" y, aún más, de la preocupación por establecer las pautas de una "crianza correcta". Es en este punto donde las características familiares y, sobre todo, las actitudes y cuidados maternos, se tornan objeto de observación, evaluación e intervención por parte de los médicos pediatras (Colangelo, 2012, p.6).

El ideal de una "crianza correcta" que ponen en juego los saberes médicos y psi supone una determinada concepción de niñez, cuerpo y relación entre niños/as y adultos/as (Colangelo, 2008). La autora repone el proceso histórico por el cual la medicina se ha erigido como voz autorizada y legítima para hablar de formas adecuadas de criar y cuidar a los niños, y muestra las disputas con otros saberes que suelen catalogarse como meros prejuicios. Esta mirada resulta de suma importancia para el análisis de la infancia trabajadora y su relación con la salud. La figura del niño trabajador vulnerable y expuesto a riesgos, naturalizados o minimizados por las familias, es un elemento común en la mayoría de los estudios citados. De hecho, si bien algunos hacen referencia a lesiones específicas provocadas por trabajar, se entiende que el trabajo infantil, genéricamente, provoca perjuicios físicos, intelectuales, morales y afectivos (Silva, 2004; Cutri et al., 2012; Orazi y Stonski, 2010). En este sentido, los aportes de Colangelo permiten mostrar la presencia de una idea de crianza infantil hegemónica según la cual el trabajo atenta contra la salud de los/as niños/as, siendo ello propiciado por la ignorancia de las familias. El análisis de prácticas, como el trabajo infantil, que ponen en juego nociones de salud e involucran el entrecruzamiento entre discursos hegemónicos y subalternos (Lorenzetti, 2012) podría ser iluminado a través de investigaciones etnográficas que den cuenta de las formas singulares en que esto se produce. En esta línea, las investigaciones de las ciencias sociales reconocen que la perspectiva de los sujetos es un elemento relevante para dar cuenta de esa singularidad y para conocer los sentidos otorgados a los procesos de salud y enfermedad ligados 
al trabajo. Y, también, un elemento que debe considerarse en la elaboración de políticas públicas vinculadas a la erradicación del trabajo infantil. No obstante, la perspectiva del actor, lejos de referirse a algo en común, adquiere acepciones disímiles en los distintos estudios revisados. Mientras que en algunos de ellos es presentada en términos de naturalización de riesgos, otros la toman en cuenta para caracterizar problemáticas locales y a partir de allí proponer estrategias de prevención y erradicación.

En los estudios citados la categoría riesgo está siempre enunciada, sobre todo en aquellos que enfatizan la necesidad de erradicar el trabajo infantil. Sin embargo, pese a estar presente no es problematizada y este ejercicio analítico podría aportar interesantes pistas para comprender mejor la perspectiva de los sujetos y contextualizarla. Suárez, Beltrán, Sánchez (2006) y Sy (2009) entienden que la conceptualización del riesgo como una categoría objetiva y abstracta, característica de la perspectiva epidemiológica clásica, si bien permite delimitar grupos poblacionales específicos o "en riesgo" para desplegar estrategias de salud focalizadas, impide explicar cómo son percibidos los procesos de salud, enfermedad, atención y cuidado por los actores sociales en contextos particulares.

Según los estudios revisados el trabajo infantil implica riesgos y aparece asociado a ciertas lesiones y accidentes. En este punto, se advierte una utilización del riesgo desde la perspectiva epidemiológica clásica, la cual permite delimitar prácticas riesgosas e incidir sobre ellas para evitar la exposición de las personas o colectivos (Breilh, 2010), en este caso la infancia trabajadora. Pero, más aún, estos estudios sostienen que si los sujetos actúan de forma arriesgada es porque naturalizan, invisibilizan o minimizan las consecuencias que el trabajo infantil tiene sobre la salud. Sy (2009) permite poner en tensión este argumento al señalar que los sujetos no miden lo riesgoso de las conductas como si éstas fueran un segmento aislable de estilos de vida particulares. Así, más que pretender que se modifiquen determinadas conductas y/o hábitos, se debe atender a los contextos locales para comprender por qué ciertos riesgos resultan o no tolerables. En esta clave puede leerse la perspectiva de las propias familias y niños/as que trabajan, pues permite echar luz sobre los significados locales del riesgo y, consecuentemente, sobre las prácticas que les resultan o no tolerables. En suma, permite poner el foco en las formas en que el riesgo es percibido más que suponer de antemano que está naturalizado o no problematizado. De todas maneras, es preciso tener en cuenta y advertir, como sugiere Lorenzetti (2012), que la propia idea de estilo de vida (de sectores populares principalmente) es concebida como un factor de riesgo desde las políticas sanitarias. 


\section{Reflexiones finales}

La revisión de estudios sobre trabajo infantil y la exploración de perspectivas alternativas a lo largo del artículo ha tenido dos objetivos centrales: profundizar en el conocimiento sobre un tema poco estudiado y contribuir a su mejor comprensión.

En este sentido, se han identificado algunos aspectos que aparecen de forma recurrente y no problematizados para ponerlos en tensión desde enfoques que permiten otras claves de lectura. En todos los estudios se reconoce la importancia de una mirada integral del trabajo infantil y de la salud. Sin embargo hay una incorporación de lo sociocultural como un factor más que conduce a explicaciones circulares generales (Sy, 2009). Algunos ejemplos son: la alusión al riesgo como una categoría objetiva, la referencia a la infancia vulnerable como una definición universal y la interpelación a las familias de los/as niños/as trabajadores desde la carencia, por lo que minimizan, naturalizan o niegan.

Una revisión crítica de estos estudios muestra, por un lado, la moralidad que permea los discursos sobre la infancia trabajadora. Se ha sugerido que el saber médico supone la existencia de una crianza correcta (Colangelo, 2008) que califica a cualquier práctica que no vaya en el sentido de garantizar "niños sanos" como riesgosa. Así, se dirige la responsabilidad de enfermar o accidentarse hacia las familias, en este caso de sectores populares, contribuyendo a estigmatizarlas (Fonseca y Cardarello, 1999; Villalta, 2010). Por otro lado, permite ver cómo las categorías que se emplean para interpretar un fenómeno resultan muchas veces descontextualizadas. Para ello, una perspectiva antropológica que aborde problemas de salud resulta relevante en tanto puede contribuir precisamente a conocer cuáles son las maneras particulares de pensar y actuar sobre el cuerpo, la salud y la enfermedad así como los comportamientos que se toman frente a ello (Uchôa y Vidal, 1994).

\section{Referencias}

ALLEMANDI, Cecilia. Niños sirvientes y "criados": el trabajo infantil en el servicio doméstico (Ciudad de Buenos Aires, fines del siglo XIX-principios del XX). En: $E l$ trabajo doméstico: entre regulaciones formales e informales. Miradas desde la historia y la sociología. Buenos Aires, Cuadernos del Ides, octubre 2015. p. 11-38.

APARICIO, Susana. Niños trabajadores en el agro argentino. Familias campesinas y de asalariados rurales. Mitos y creencias en torno al trabajo infantil rural. XXVII Congreso de la Asociación Latinoamericana de Sociología. Buenos Aires, 2009 $<$ http://cdsa.aacademica.org/000-062/1876.pdf $>$. 
APARICIO, Susana; AGUILERA María Eugenia; RE, Daniel Alberto. El trabajo infantil en el agro argentino. En: Mariela Macri (comp.). Trabajos infantiles e infancias. Investigaciones en territorio (Argentina, 2005-2010). Buenos Aires: Editorial Stella, 2012. p. 165-204.

BERGESIO, Liliana; SPIONE, Claudia, VARGAS, Mabel. Trabajo infantil en basurales de Jujuy. Observatorio de trabajo infantil y adolescente, $2010<$ unicef. org/argentina/spanish/PUBLI_Trabajo_infantil_basurales_jujuy_WEB.pdf $>$ (10 dic. 2017).

BREILH, Jaime. La epidemiología crítica: una nueva forma de mirar la salud en el espacio urbano. Salud colectiva, v. 6, n. 1, p. 83-101, $2010<10.1590 /$ S1851$82652010000100007>$.

BRUNATTI, Olga; COLÁNGELO, Adelaida; SOPRANO, Germán. Observar para legislar. Métodos etnográficos e inspección del trabajo en Argentina a principios del siglo XX. En: Sergio Visacovsky, Rosana Guber (comps.). Historia y estilos de trabajo de campo antropológico en la Argentina. Buenos Aires: Antropofagia, 2002. p. 78-127.

CARDARELLI, Graciela; DORREGO, Gabriela; NIRENGERB, Olga. Mi historia, tu historia: el trabajo infantil desde la perspectiva de las familias. En: El trabajo infantil en la Argentina. Análisis y desafíos para la política pública. Buenos Aires: OIT, 2007. p. 279-307.

COLANGELO, Adelaida. Evaluando la crianza: modos de intervención sobre niños y familias en el espacio del control pediátrico de la salud infantil. En: Actas del Tercer Congreso Latinoamericano de Antropología, Santiago de Chile: ALA, 2012.

COLANGELO, Adelaida. La crianza en disputa: un análisis del saber médico sobre el cuidado infantil. En: Actas del VIII Congreso Argentino de Antropología Social. Salta, 2008.

CUTRI, Adrián; HAMMERMÜLLER, Erica; ZUBIETA, Ana; MÜLLER OPET, Beatríz; MIGUELEZ, Lilia. Trabajo infantil: una problemática social que nos compromete. Archivos Argentinos de Pediatría, v. 110, n. 4, p. 350-358, 2012 $<10.5546$ /aap.2012.350>.

DURO, Elena. Enfoque integral de derechos y trabajo infantil: oportunidades y desafíos. En: Susana Aparicio et al. El trabajo infantil en la Argentina. Análisis y desafios para la política pública. Buenos Aires: OIT, Ministerio de Trabajo, Empleo y Seguridad Social, 2007. p. 53-74.

FONSECA, Claudia; CARDARELlO, Andrea. Direitos dos mais e menos humanos. Horizontes Antropológicos, v. 5, p. 83-121, $1999<10.1590 / \mathrm{S} 0104-$ $71831999000100005>$.

GALENDE, Beatríz; PICCO, Esther. Trabajo infantil su impacto en la constitución subjetiva. Kairos, v. 5, n. 8, 2001.

HALPERÍN, Verónica. Trabajo infantil e infancia: un estado del arte de la investigación en Argentina (2009-2011). En: Mariela Macri (comp.). Trabajos infantiles e infancias. Investigaciones en territorio (Argentina, 2005-2010). Buenos Aires: Editorial Stella, 2012. p. 39-83. 
IPEC. Niños en trabajos peligrosos: lo que sabemos, lo que debemos hacer. Ginebra: OIT, 2011.

LOBATO, Mirta. Las rutas de las ideas: "cuestión social", feminismos y trabajo femenino. Revista de Indias, v. 73, n. 257, p. 131-156, $2013<10.3989$ / revindias.2013.006>.

LOBATO, Mirta. Historia de las instituciones laborales en Argentina: una asignatura pendiente. Revista de Trabajo, v. 3, n. 4, p. 145-154, 2007.

LORENZETTI, Mariana. La dimensión política de la salud: las prácticas sanitarias desde las comunidades peri-urbanas Wichi del depto. de San Martín (Salta). Publicar, v. 10, n. 12 , p. $65-85,2012$.

MACRI, Mariela; FORD, Myriam; BERLINER, Carolina; MOLTENI, María Julia. El trabajo infantil no es un juego. Estudios e investigaciones sobre trabajo infantoadolescente en Argentina (1900-2003). Buenos Aires: Editorial Stella, 2005.

MACRI, Mariela. Proyecto Ubacyt 078 Trabajo infantil e infancia. En: Mariela Macri (comp.). Trabajos infantiles e infancias. Investigaciones en territorio (Argentina, 2005-2010). Buenos Aires: Editorial Stella. 2012. p. 21-37.

MASTRANGELO, Andrea. Exploraciones etnográficas sobre trabajo infantil y minería en Argentina. Revista Virtual Redesma, v. 3, n. 1, p. 56-65, 2009 < biblioteca. ribei.org/277/1/redesma06.pdf> (30 abr. 2018).

NOCETI, María Belén. El trabajo infantil como estrategia de sostén de las familias pobres en la Argentina, la necesidad de rediseñar el objeto de las políticas públicas. Revista Acciones e Investigaciones sociales, v. 27, p. 171-194, 2009.

NOCETI, María Belén. Niñez trabajadora y políticas públicas en Bahía Blanca. Jornadas Estado, Familia e Infancia en Argentina y Latinoamérica: problemas y perspectivas de análisis. Buenos Aires, 2010.

OIT. Trabajo infantil y su impacto sobre la salud: manual de formación para equipos de salud en el marco de la estrategia de prevención y erradicación del trabajo infantil en la Argentina. Ministerio de Trabajo, Empleo y Seguridad Social. Buenos Aires: OIT, 2015 <flacso.org.ar/wp-content/uploads/2015/12/Trabajo-infantil-y-su-impactosobre-la-salud.pdf> (29 nov. 2017).

ORAZI, Virginia; STONSKI, Teresa. Trabajo infantil: una problemática social y compleja. Sociedad Argentina de Pediatría. Pronap, 2010. p. 68-104. <sap.org.ar/ docs/educacion/Trabajo_infantil.pdf> (10 nov. 2017).

QUEIROLO, Graciela Amalia. Vendedoras: género y trabajo en el sector comercial (Buenos Aires, 1910-1950). Estudos Feministas, v. 22, n. 1, p. 29-50, $2014<10.1590 /$ S0104-026X2014000100003>.

RAUSKY, María Eugenia. Perspectivas sobre el trabajo infantil en la Argentina: un análisis de las investigaciones desarrolladas en Ciencias Sociales. Revista Estudios Regionales y Mercado de Trabajo, v. 2, p. 177-200, 2009.

RAUSKY, María Eugenia. Los niños y niñas que trabajan: relaciones generacionales y de género. En: Amalia Eguía; María Susana Ortale; Juan Ignacio Piovani (comps.). Género, trabajo y políticas sociales. Ciudad Autónoma de Buenos Aires: Clacso, 2015. p. 111-133. 
SILVA, María Alejandra. Infancia y trabajo infantil en la historia argentina. Clivajes: Revista de Ciências Sociais, n. 1, s. p. 2014.

SILVA, María Alejandra. Trabajo infantil y salud: balance y desafíos. En: Mariela Macri (comp.). Trabajos infantiles e infancias. Investigaciones en territorio (Argentina, 2005-2010). Buenos Aires: Editorial Stella. 2012. p. 205-232.

SILVA, María Alejandra. Trabajo infantil y salud: cien años después de Bialet Massé. Simposio: A cien años del informe de Bialet-Massé: el trabajo en la Argentina del siglo XX y albores del siglo XXI, 2007 <trabajo.gob.ar/left/estadisticas/otia/centroDoc/ verDocumento.asp? $\mathrm{id}=65>$.

SUÁREZ, Roberto; BELTRÁN, Elsa María; SÁNCHEZ, Tatiana. El sentido del riesgo desde la antropología médica. consonancias y disonancias con la salud pública en dos enfermedades transmisibles. Antípoda, n. 3, p. 123-154, 2006.

SURIANO, Juan. El trabajo infantil en la historiografía y ciencias sociales argentinas. En: El trabajo doméstico: entre regulaciones formales e informales. Miradas desde la historia y la sociología. Buenos Aires: Cuadernos del Ides. 2015. p. 39-43.

SURIANO, Juan. Niños trabajadores: una aproximación al trabajo infantil en la industria porteña de comienzos del siglo. En: Diego Armus (comp.). Mundo urbano y cultura popular. Buenos Aires: Sudamericana, 1990. p. 253-279.

SY, Anahí. Una revisión de los estudios en torno a enfermedades gastrointestinales: en busca de nuevas alternativas para el análisis de los procesos de salud-enfermedad. Salud Colectiva. v. 5, n. 1, p. 49-62, $2009<10.18294 /$ sc.2009.230>.

SZULC, Andrea. Antropología y niñez: de la omisión a las 'culturas infantiles'. En: Guillermo Wilde; Pablo Schamber (comps.). Cultura, comunidades y procesos contemporáneos. Buenos Aires: SB, 2006. p. 25-50.

UCHÔA, Elizabeth; VIDAL, Jean Michel. Antropología médica: elementos conceituais e metodológicos para uma abordagem da saúde e da doença. Cadernos de Saúde Pública, v. 10, n. 4, p. 497-504, 1994 <10.1590/S0102-311X1994000400010>.

VILLALTA, Carla. Introducción. En: Carla Villalta (comp.). Infancia, justicia y derechos humanos. Bernal: Universidad Nacional de Quilmes, 2010. p. 9-19.

ZAPIOLA, María Carolina. Los niños entre la escuela, el taller y la calle (o los límites de la obligatoriedad escolar). Buenos Aires, 1884-1915. Cadernos de Pesquisa, v. 39, n. 136 , p. $69-81,2009<10.1590 /$ S0100-15742009000100005>.

Recibido el: 11 dic. 2017.

Aprobado el: 30 abr. 2017.

Autora correspondiente:

Laura Frasco Zuker

Bernardo de Irigoyen, 650 - CP 1072

Ciudad Autonoma de Buenos Aires, Argentina

LAURA FRASCO ZUKER <laurefz@gmail.com>

Doutoranda en Antropologia Social, Instituto de Altos Estudios Sociales de la Universidad Nacional General San Martín (Idaes, Unsam, Ciudad Autonoma de Buenos Aires, Argentina). Profesora en la Universidad de Buenos Aires (UBA, Ciudad Autonoma de Buenos Aires, Argentina; grid.7345.5) y en la Universidad Nacional de La Matanza (UNLaM, San Justo, Buenos Aires, Argentina).

ORCID: https://orcid.org/0000-0002-8328-7267 